\title{
Qualitative lens to assessing the ground level implementation of conditional cash transfer scheme in India
}

\author{
Shantanu Sharma ${ }^{1 *}$, Devika Mehra ${ }^{2}$, Harsavardhan Nayak ${ }^{1}$, M. M. Singh ${ }^{1}$
}

\author{
${ }^{1}$ Department of Community Medicine, Maulana Azad Medical College, Delhi, India \\ ${ }^{2}$ Public Health Consultant, Medeon Science Park, Malmo, Sweden
}

Received: 22 April 2018

Accepted: 23 May 2018

\author{
*Correspondence: \\ Dr. Shantanu Sharma, \\ E-mail: shantanusharma145@gmail.com
}

Copyright: () the author(s), publisher and licensee Medip Academy. This is an open-access article distributed under the terms of the Creative Commons Attribution Non-Commercial License, which permits unrestricted non-commercial use, distribution, and reproduction in any medium, provided the original work is properly cited.

\begin{abstract}
Background: Conditional cash transfer scheme, known as Janani Suraksha Yojna (JSY) is an innovative concept on the lines of behavioral economics. The study aimed to investigate factors associated with effective implementation of scheme at the community in Delhi, India.

Methods: We did qualitative study to investigate the implementation factors related to JSY by conducting in depth interviews with 50 mothers in a span of three months. All the interviews were conducted in local language (Hindi) by the principle investigator. The data were collected through semi-structured interviews, which were later transcribed and recorded in Microsoft-Excel sheet. The themes were developed inductively, meaning that they were anticipated from the design of interview, during literature review and deductively meaning that they were not anticipated during design of the interview.

Results: The mean $( \pm \mathrm{SD})$ age of the women was $25( \pm 3.5)$ years. More than three-forth of the mothers were not aware of the JSY scheme. Most of the women claimed limited support from accredited social health activist at the time of delivery. Provision of respectful maternity care was poor with women reporting episodes of verbal abuses, and arrogant attitude of the staff. Issues in utilization of the scheme encountered in study were untimely disbursement of money, problems in the process of BPL cards formation, lack of awareness on the scheme, banking illiteracy etc.

Conclusions: Amidst the wider geographic reach and accessibility of the scheme by the poor, there exists some barriers to its effective implementation and practical challenges, which need immediate addressal by program managers.
\end{abstract}

Keywords: Awareness, Economics, Health worker, Incentive, Maternal health

\section{INTRODUCTION}

The prime target of Sustainable Development Goals is to reduce maternal mortality rate (MMR) to less than seventy per hundred thousand live births by $2030 .{ }^{1}$ Two of the major contributing factors to MMR are postpartum hemorrhage and sepsis. ${ }^{2}$ Institutional delivery and care by skilled birth attendants are the most effective measures towards reducing these clinical complications. India's flagship program, National Health Mission launched conditional cash transfer scheme (Janani
Surakhsha Yojna; JSY) to incentivize institutional delivery and reduce maternal and neonatal mortality in rural and urban areas. Conditional cash transfer, a social assistance program, is an initiative of demand side financing where government transfers money to beneficiaries who meet certain criteria. It is an innovative financial mechanism aimed at improving maternal and child health. ${ }^{3}$ Common review mission (2016) reported that JSY is widely implemented across the country but there have been issues regarding delay or non-payment of money in many states. ${ }^{4}$ On the demand side, awareness 
about the program has increased but misunderstandings persist in the communities alongside dissatisfaction and under-utilization of the scheme. There have been multiple challenges in operationalizing JSY effectively on ground from the supply side perspectives and the consequent issues like non-activated redressal mechanism, nonprovision of advance travel allowance to Accredited Social Health Activist (ASHA), safety concerns for ASHA in escorting women at odd timings, lack of regular trainings etc. ${ }^{5}$

However, most of the evidences come from rural settings and states under Empowered Action group. The urban angle to the successes and drawbacks in the scheme implementation is limited by its existing literature in the public domain. ${ }^{6}$ Delhi, high performing state, has a large population residing in slums and resettlement colonies majority of which belong to below poverty line or low socio-economic background. The various interacting factors that interplay towards creating an environment influencing the utilization and successful implementation of the scheme need to be understood in every geographic and socio-demographic context. The study aimed to investigate factors associated with effective implementation of the scheme at the community level in Delhi, India and understand the barriers in accessing the same. The secondary aim of the study was to assess the knowledge and utilization of the JSY scheme.

\section{METHODS}

This study adopted a qualitative approach to investigate the implementation factors related to JSY by conducting in depth interviews with 50 mothers. This study was conducted in the span of 3 months in the northeast district of Delhi (Gokulpuri), India. The Primary health center in Gokulpuri is run by the department offering services of maternal and child care along with routine outpatient department (OPD) services. The researchers purposively selected a block that was chosen where all the target beneficiaries (mothers belonging to Scheduled caste/tribe/other backward classes) were interviewed. The list of beneficiaries and their contact addresses were obtained from the records available at the health centre. All the interviews were conducted in local language (Hindi) by the principle investigator. An individual interview schedule comprising of three sections was designed for this study.

Phase I of the study included structured questions to obtain general demographic information, anthropometric measurements, and obstetric details. Phase II was an open-ended exploratory interview. This focused on details of the components in the scheme, and barriers in receiving cash transfer. The mothers participating in the research were asked to share the problems they faced while accessing the scheme and their satisfaction with the services provided in the hospital where they delivered. Phase III concluded the interview with the interviewer summarizing the information provided by the respondent and capture if any information has been missed. Verbal informed consent was obtained from the participants before the interviews were conducted. The participants were assured of confidentiality of their data.

The study was approved by the institutional ethical committee. We further did advocacy with the medical officers to fasten the process of delivering cash in time to the JSY beneficiaries. None of the participants refused to participate. All the interviews were recorded manually and later transcribed and translated into English (when required). The data were collected through semistructured interviews, which were later transcribed and recorded in Microsoft-Excel sheet. The lines of the text were coded (ie, assigned a number) into different categories. Thus, in each category lines of text that represented similar themes or topics were grouped together. The themes were developed inductively, meaning that they were anticipated from the design of interview, during literature review and deductively meaning that they were not anticipated during design of the interview.

\section{RESULTS}

The mean $( \pm \mathrm{SD})$ age of the women was $25( \pm 3.5)$ years. Around $22 \%$ (11) of the participants belonged to backward class. More than two-third of the participants $(68 \%)$ were residing in the area for more than 5 years. All the women participating were housewives and were registered at the Gokulpuri health centre during pregnancy. More than three-forth of the mothers were not aware of the JSY scheme. Thirty-five women out of fifty did not receive any assistance from the government.

\section{Components of JSY}

The three components of the scheme including the support of accredited social health activist (ASHA) in promoting institutional delivery, mother friendly support from the hospital during perinatal period, and cash transfer part has been presented.

Accredited Social Health Activist (ASHA) support during delivery: Majority of the women reported that they have received support of ASHA in terms of counseling for institutional delivery but there was not enough support during delivery. ASHA supported them in selecting the institution for delivery. However, most of them didn't escort them to hospital or stay with them there which is not in line with the JSY guidelines.

I was in great pain at night when my husband approached the ASHA worker and asked for help. She was bit hesitant to come since it was too late at night and all she did was making a call at 102 and asked for an ambulance. There was no other women available at that time to accompany me. After ASHA refused to accompany, I requested my neighbor and she helped. 
Most of the women delivered at hospital told that they were discharged after 48 hours of the delivery from the hospital but five of them were discharged early (within 48 hours of delivery). Many women reported breastfeeding of their child within an hour of the delivery but the practice of feeding pre-lacteal foods to their newborns was also common within the hospital premises. Women informed the investigator that they were neither advised nor stopped from giving pre-lacteal feeds to newborns in the hospital. So they continued with tradition of giving pre-lacteal feeds (honey) to their child. Many women complaint during the interview about the maternity services provided at the government hospital where they were enrolled. At the time of discharge from the hospital. Most of the women were told about exclusive breastfeeding only at the time of discharge from the hospital. The cleanliness in the wards and the bathroom was another major issue highlighted by the women during the interview. However, the staff on daily basis cleaned them but at most of the times, they used to stink. There were complaints among the women regarding the unsatisfactory behavior of the nursing staff and inattentive attitude at the time of call or need.

We could not afford private hospital so went to a government hospital for delivery. The staff inside the labour room was arrogant and shouting at most of us.

We had to share bed with two or sometimes three women, which was very uncomfortable.

We used to receive food from the kitchen at the hospital that used to be unhygienic and had a poor quality.

Only at the time of discharge from the hospital, we were told about breastfeeding and its benefits. If I would had been asked to avoid giving honey at the time of birth, I would have definitely not did that but I was kept ignorant.

Thirty-nine out of fifty women received cash within one installment whereas one woman received it in two installments and for the rest ten women; the application was either still in process or have not yet received the money. On being asked about the time after delivery at which they received the money, only one woman responded that she received it immediately after birth. Only few amongst them reported to have received it within one month, otherwise majority received it after three months or later. Further to the discussion, interviewer investigated about the difficulties these women faced while accessing the money. Most of the women reported not having BPL cards as the prime reason of all the problems. Many had issues pertaining to lack of accounts for the transfer of money or knowledge to operate them. Some of the women raised the issues about the lack of documents or missing documents required while submitting application for the scheme. In addition, few women had to visit the facility multiple times for the claim or submission of papers and hence were demotivated at that front. The low amount of incentive Vis a Vis the amount of efforts while applying for the scheme one had to pay was discouraging for the participants. There was a complete lack of awareness about what was the money in the scheme meant for among women. Most of the women had spent it on their child or gave it to husband for buying ration for the house. Only few had told that they spent some part of the money on their diet.

Our Below Poverty Line (BPL) cards have not been made since we didn't have adequate proofs of residence and other related documents. We were told that if we get a document signed by the local Member of the Legislative Assembly (MLA) stating that we are living below poverty line, the medical officer will approve it. So, we got a letter signed by the MLA and hence we could avail the scheme.

We have visited the health centre number of times and every time we were returned saying that the money has not come yet or documents are incomplete. It takes Rs. 20-30 every time to commute from home to the health centre. We have already spent so much of money just to get Rs. 600 into an account, which we do not even access.

We have never opened or operated an account. It was difficult for us to open it and operate it since our husbands normally did it. Moreover, it made no sense to spend Rs. 1000 in opening an account just to receive Rs. 600 .

We don't remember how we spent that little money, it must have been spent while buying ration for the home.

I spent the money for buying clothes for my child since it was winter and had to buy sweaters for him.

The money I received was so less that even I cannot buy a kilogram of ghee for myself, forget about any other thing. My husband just spent it on buying items for our house.

\section{DISCUSSION}

This empirical study presents findings of the challenges and barriers in implementation and utilization aspects of JSY scheme from the beneficiaries. Although studies have claimed JSY's role in improving institutional delivery rates in India but the objective of the scheme for reducing neonatal mortality rate and other key issues were not met. ${ }^{7}$

In our findings, most of the women had not heard about the JSY scheme. The term JSY was synonymous with receiving cash after delivery but the details of the scheme were not known. This point towards ineffective counseling on the part of ASHA or other midwives who didn't explain about the scheme in detail. The consequences of the same may result in underachievement in the outcomes of the program. These results are contradictory to studies from other researchers 
where a large proportion of the women reported that they were aware of the scheme. ${ }^{6,8,9}$ Our findings indicate that support from an ASHA to the women is restricted to counseling and decision making process for institutional delivery. A majority of them were still not being escorted or supported in the facility. The responsibility of arranging transport during labour pain was not fully supported by ASHA to most of the women. This is perhaps very important for ASHA to be with the mother and child at the time of delivery and immediate postdelivery phase where she could save her from not only any immediate intra- or post-natal complications but also help initiate early and exclusive breastfeeding. A previous study by UNICEF through a large household survey also reported limited involvement of ASHAs in this component of the JSY scheme. ${ }^{10}$ Another qualitative study from Odisha however depicted greater engagement and support by ASHA at various stages. The study revealed that ASHA apart from accompanying the expectant mother to the hospital and staying at the facility also provided psychological support. ${ }^{11}$

Most of the women were provided counseling on breastfeeding in the present study but only at the time of discharge from the hospital. Roy et al in his study from Odisha also quoted similar responses from participants where the mother confirmed to have received counseling on exclusive breastfeeding (EBF). ${ }^{11}$ Needless to say, that the counselling for EBF should start much before delivery during pregnancy by ASHA or midwives but timely reinforcement of the same by the nurses in facility is even more important. Most of the women rated hospitals unsatisfactory regarding mother-friendly environment and pointed at incidents of arrogant attitude of the staff. In addition, unhygienic food and unclean surroundings in the wards made accessibility of the women in the government hospital even more unsafe. These instances or responses violates the ethical base of essential elements of health care, which stands for respectful maternity care. Chaturvedi et al in his study across 3 districts of Madhya Pradesh also highlighted disrespectful attitude of the staff with episodes of abuse and ignorance towards the patients. ${ }^{12}$ The receipt of the JSY money was not that smooth and easy for roughly one-fourth of the respondents who either received it in multiple installments or were still awaiting for the same at the time of the survey. The corresponding figures from some of the other studies are in congruence with our study, but in some other studies, they are even lower. ${ }^{13,14}$ Mahawar et al in their research from Madhya Pradesh reported that two-third of the women had to wait for about a month before receiving the money. ${ }^{15}$ This was stated as one of the most discouraging element of the scheme during the interviews. The common review mission report 2016 also mentioned about the similar drawbacks of the scheme from many states. Although, the JSY guidelines by the ministry has clearly described the proper mechanisms for addressing the delays and emphasized on dealing these unreasonable delays seriously, yet the implementation is so poor.
Many women faced problem of missing BPL cards while submitting the documents for verification. Most of them affirmed their low socio-economic strata to be eligible for the scheme, yet didn't have the BPL cards as proofs. Vikram et al in his study from Delhi also reported that only $7.5 \%$ women had any proof for their backward or BPL status. ${ }^{6}$ Ram et al in his publication in 2009 concluded that the distribution of BPL cards in India is not fair and three-fifth of the poorest didn't have BPL cards. ${ }^{16}$ This problem not only deprives this marginalized population from availing benefits of social welfare schemes but also other health care schemes such as JSY. Other common difficulties faced while receiving money for JSY scheme were missing other essential documents for filing application, challenges in opening and operating bank accounts and multiple visits to the health centers required for complete submission of the papers. Doke et al in his study from Maharashtra highlighted similar difficulties while accessing scheme benefits in varying magnitudes. ${ }^{9}$ Difficulty in arranging documents has also been the key issue in West Bengal as reported in his study by Santra et al. ${ }^{17}$ Residents of Chandigarh added another issue to this list of problems which was the low amount of benefit in the scheme which was demotivating while accessing it. ${ }^{18}$ This issue was also reported in a qualitative multi-centric study from three states (Uttar Pradesh, Madhya Pradesh and Jharkhand) in India. ${ }^{19}$ In the current scenario of inflation and rising price of essential commodities, the monetary incentive seems low from the perspectives of poor population residing in urban areas.

The objective of the initiative was defeated when majority of the women spent JSY money on the purposes other than that it was meant for. Most of the women spent it on buying ration for home, a smaller proportion bought different things for her child and in few cases, husbands used it for some other purposes. Similar situation persists in one of the city from Madhya Pradesh where only onethird women claimed to have used JSY money on their nutrition. Rest of the mothers reported that either they used it on medicines, clothes or on food for the child; the husband took it for some other purposes and spent on household expenditures. ${ }^{20}$ Midwives and ASHA can only address this gap between receiving and utilizing the money for its purpose with their effective communication and counseling skills during the antenatal period.

Although limited by its subjectivity and feasibility, we did try to bring in credible findings in the present study through keeping scientific and systematic vigor. But the generalizability of the findings might be a challenge due to its small sample size. Keeping in mind the limited resources and time for the study, we restricted to selected domains of JSY.

\section{CONCLUSION}

At a broader level the scheme has undoubtedly proven to be a cornerstone in increasing the institutional delivery 
rate in India due to monetary incentivization. Amid the wider geographic reach and accessibility of the scheme by the poor, there exists some barriers to its effective implementation and practical challenges. Our study though reflects JSY situation from a small locality within a state, but supports the findings from many others communities across India. From the multitude of responsibilities and challenges, policy makers have to prioritize JSY implementation by understanding its enabling and demotivating factors for timely corrective measures. Some of the issues in utilization of the scheme encountered in our study were untimely disbursement of money, problems in the process of BPL cards formation, lack of awareness on the benefits and purposes of the scheme, banking illiteracy and lack of mother friendly facilities for receiving respectful maternity care.

\section{Funding: No funding sources}

Conflict of interest: None declared

Ethical approval: The study was approved by the Institutional Ethics Committee

\section{REFERENCES}

1. United National development program. Sustainable development goals 2030. Available from: http://www.undp.org/content/undp/en/home/sustainable -development-goals/goal-3-good-health-and-wellbeing/targets/. Accessed on 1 March 2018.

2. Datta D, Datta PP. Maternal Mortality in India: Problems and Strategies. Asian J Med Res. 2013;2(1):33-5.

3. Furniturewala A, Pareek S, Mookerjee S. Impact of JSY and JSSK programs in the District of Pune. https://www.researchgate.net/publication/282503464_I mpact_of_JSY_and_JSSK_Programs_in_the_district_of _Pune. Accessed on 1 March 2018.

4. Ministry of Health and Family Welfare. Common review mission report 2016. National Health Mission. Government of India. 2017.

5. Bharti K. Implementation of Janani Suraksha Yojna. Available at: http://www.esocialsciences.org/eSSH_ Journal/Repository/4_Janani\%20Suraksha\%20Yojana_ Kavita\%20Bhatia.pdf. Accessed on 10 April 2018.

6. Vikram K, Sharma AK, Kannan AT. Beneficiary level factors influencing Janani Suraksha Yojana utilization in urban slum population of trans-Yamuna area of Delhi. Indian J Med Res. 2013;138(3):340-6.

7. Powell-Jackson T, Mazumdar S, Mills A. Financial incentives in health: New evidence from India's Janani Suraksha Yojana. J health Econ. 2015;43:154-69.

8. Mandal DK, Kaur P, Murhekar MV. Low coverage of Janani Suraksha Yojana among mothers in 24-Parganas (South) of West Bengal in 2009. BMC Proceedings. 2012, 6(Suppl 1):O3.
9. Doke PP, Gawande UH, Deshpande SR, Gadgil M. Evaluation of Janani Suraksha Yojana (JSY) in Maharashtra, India: Important Lessons for Implementation. IJTDH. 2015;5(2):141-55.

10. UNICEF. Coverage Evaluation Survey 2009. Ministry of health and family welfare. 2009.

11. Roy S, Sahu B. Can ASHA be the ray of hope for providing $\mathrm{MCH}$ services in Odisha, India? Exploring through a qualitative study. J Glob Health Care Sys. 2013;3(2).

12. Chaturvedi S, Costa AD, Raven J. Does the Janani Suraksha Yojana cash transfer programme to promote facility births in India ensure skilled birth attendance? A qualitative study of intrapartum care in Madhya Pradesh, Global Health Action. 2015;8(1):27427.

13. Mukhopadhyay DK, Mukhopadhyay S, Mallik S, Nayak S, Biswas AK, Biswas AB. Exploring the Bottlenecks: An Assessment of the Implementation Process of Janani Suraksha Yojana in the State of West Bengal, India. Int J Med Public Health. 2018;8(1):2933.

14. United Nations Population Fund -India. Concurrent Assessment of Janani Suraksha Yojana (JSY) in selected states. Bihar, Madhya Pradesh, Orissa, Rajasthan, Uttar Pradesh. UNFPA, New Delhi, India. 2009;1-68.

15. Mahawar P, Anand S, Dixit S, Bhagwat AK, Sakalle S, Yesikar V. Evaluation of Different Aspects of Janani Suraksha Yojna in Indore District, Madhya Pradesh. Natl J Community Med. 2013;4(3):512-5.

16. Ram F, Mohanty SK, Ram U. Understanding the distribution of BPL Cards: all-India and selected states. Econ Pol Weekly. 2009;44:66-71.

17. Santra S, Lahiri S, Biswas A, Shrivastava P. Utilization of maternal health care services with special emphasis on Janani Suraksha Yojana in a slum of Kolkata, West Bengal. Int J Med Public Health. 2015;5:225-7.

18. Goel S, Sharma D, Rani S. Factors influencing Janani Suraksha Yojana utilization in a northern city of India. Int J Reprod Contracept Obstet Gynecol. 2017;6:575-9.

19. Vellakkal S, Reddy H, Gupta A, Chandran A, Fledderjohann J, Stuckler D. A qualitative study of factors impacting accessing of institutional delivery care in the context of India's cash incentive program. Soc Sci Med. 2017;178:55-65.

20. Gupta SK, Pal DK, Tiwari R, Garg R, Sarawagi R. Assessment of Janani Suraksha Yojana (JSY)-in Jabalpur, Madhya Pradesh: knowledge, attitude and utilization pattern of beneficiaries: a descriptive study. Int J Curr Biol Med Sci. 2011;1(2):06-11.

Cite this article as: Sharma S, Mehra D, Nayak H, Singh MM. Qualitative lens to assessing the ground level implementation of conditional cash transfer scheme in India. Int J Reprod Contracept Obstet Gynecol 2018;7:2742-6. 